\title{
Analgesic Drug Development for Children: A History of Shortcomings ... Until Now
}

This article was published in the following Dove Press journal:

Journal of Pain Research

\author{
Andrew Dinh (D) \\ Ardin Berger' \\ Elliot Krane $\mathbb{D}^{1,2}$ \\ 'Department of Anesthesiology, \\ Perioperative and Pain Medicine, Stanford \\ University School of Medicine, Stanford, \\ CA, USA; ${ }^{2}$ Department of Pediatrics, \\ Stanford University School of Medicine, \\ Stanford, CA, USA
}

Correspondence: Andrew Dinh Email atdinh@stanford.edu
With hundreds of pharmaceutical companies internationally, each sharing a portion of a global, multi-trillion dollar business, and with international drug approval regulations varying widely in terms of restrictions, timing, and cost, each decision made by pharmaceutical companies in planning the development of a new drug has immense financial consequences. Grünenthal, a family-owned pharmaceutical company that now employs over 4500 individuals, has funded and executed multiple clinical drug trials of the analgesic tapentadol, a novel molecule with both muopioid and SNRI-like (serotonin and norepinephrine reuptake inhibitor) properties that have been shown to be effective in the treatment of acute and chronic pain in adults. In taking the necessary steps to demonstrate pharmacokinetics, efficacy and, safety in the pediatric population for their drug, Grünenthal has established a precedent and set the bar for other pharmaceutical companies - one that has remained largely absent from the most recent drug releases.

Medical advances and new drug development have grown at a tremendous pace, and continue to reach new heights year after year. In 1996, the United States Food and Drug Administration (FDA) approved a record-breaking 50 new drug approvals. ${ }^{1}$ In the year 2018, another benchmark was set when the FDA issued approvals for 61 new drugs. ${ }^{1}$ While used as evidence of the progress of the economies of medically advanced countries, these numbers do not reflect the myopic perspective that predominates the world of pharmaceutical development in ignoring $25 \%$ of the population - children.

Of the 61 new drug approvals in 2018, only 4 approvals were for the pediatric age group (ages $2-17)^{2}$ in spite of the fact that children and adolescents represent one-quarter of the population, suffer from many of the same ailments as do their elders, and from many more that are unique to their age group. Today, only about half of analgesic medications used in either inpatient or outpatient settings have been thoroughly evaluated for efficacy and safety, and have dosing guidelines approved by the international regulatory agencies for use in pediatrics. ${ }^{2}$ The number of analgesic medications approved in ages less than 2 years, including preterm infants, is even more humbling at only $35 \% .{ }^{10}$ Yet in spite of the lack of clinical trials by industry and thorough evaluation by governmental bodies, analgesics are still widely prescribed in pediatrics and are used "off-label," which increases the risk to the patient for both toxicity and lack of efficacy, as well as medicolegal exposure for the healthcare provider. ${ }^{5}$ 


\section{Pediatric Pharmaceutical Development Regulations in the US}

FDA REQUIRES pediatric drug labelling (Studies not yet required)

FDA Modernization Act: Patent Exclusivity with Pediatric Studies

"The Pediatric Rule"

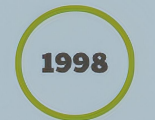

1997
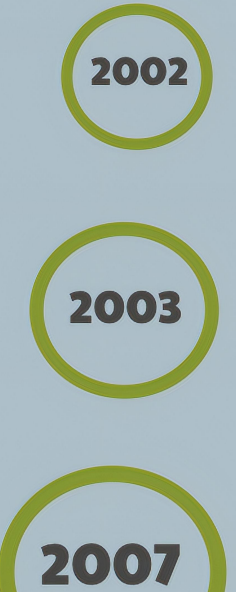

BPCA and PREA renewed in Congress

effectiveness of new

drugs and biological products in pediatrics

"The Pediatric Rule" challenged by

manufacturers and

eventually overturned Children Act" (BPCA)

Continuation of FDA

"Modernization Act"

"Pediatric Research

Equities Act" (PREA)

Continuation of "The

Pediatric Rule" requiring

in pediatric drug

development

\section{BPCA and PREA Made \\ Permanent by Congress}

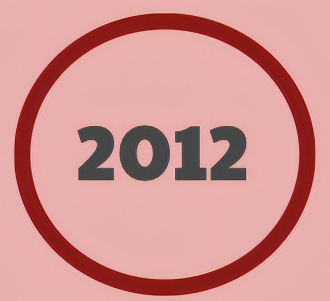

"Best Pharmaceuticals for

Now Provides NIH funding

safety and efficacy studies

The United States Food and Drug Administration has required safety and efficacy studies in the pediatric population for new drug developments since 2012 and yet, there still remains a large gap in approved medications in pediatrics

\section{Pediatric Pharmaceutical Representotion}

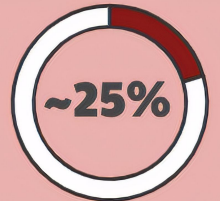

Pediatric Population

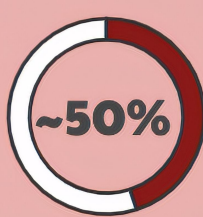

FDA Approved Analgesics
Although the pediatric population makes up $25 \%$ of the population in the United States, only $50 \%$ of the analgesic medications used in pediatrics has FDA approval for use in pediatrics.

Figure I Historical timeline of drug development milestones in the United States of America. Note: Data from these studies. ${ }^{1-4}$ 
These statistics hallmark one of the realities of pharmaceutical progress: with competition to be the quickest to bring new medications to market also comes the incentive to bypass important steps that confer benefit to society but are, at the same time, deemed unnecessary for the sake of corporate profit. In the case of pain medication, this means that the pediatric population is overlooked, and is deprived of evidence for safe and effective medication administration.

Of course, pharmaceutical research and development for children has many challenges. Ethical considerations, financial burdens, and time constraints make it difficult and expensive for the pharmaceutical industry to allocate their resources to what is, in essence, an ethical and altruistic duty that does not assure their return on investment. To address the problem of the misaligned interests of pharmaceutical companies, who have well-defined fiduciary obligations to their stockholders, and the vulnerable patients and their healthcare providers, it has been necessary to have intervention by governments to align public health and corporate priorities.

For example, since 1994 there have been several regulatory programs and statutory requirements put in place by the US FDA and the US Congress in order to realign the visions towards a collective goal. However, experience shows that there is still much more to be done in hopes of reaching the endpoint of safer healthcare practice and overall affordable and accessible healthcare for our vulnerable populations. Today, even with the presence of the FDA requirements (Figure 1), only around $50 \%$ of all analgesics used in children are "approved" by the FDA for use in pediatrics.

Grünenthal's development of tapentadol for the pediatric population has shown very promising safety and efficacy results - comparable to those found in the adult population. By first using simulation models on known volume of distribution and clearance data, an oral, weightbased tapentadol dose was predicted and used for subsequent pediatric clinical trials. Using these models, Grünenthal then used the predicted oral formulation dosing regimens and designed and executed studies that defined pharmacokinetics and efficacy for their trial drug in children. In both single-blind and double-blind randomized control studies, Grünenthal has been able to show short-term benefits of their new pain medication in children. Confirmation of the short-term effects in the pediatric population from these studies allow health care providers to prescribe the oral formulation of tapentadol with confidence in its dose, predicted effects and potential side effects. ${ }^{69}$
In an ideal world, all drugs used in the pediatrics would have strong evidence-based dosing regimens and appropriate drug labelling. History and current data tell us that this vision has many challenges, ranging from simple financial considerations to complex ethical hurdles, all of which have proven difficult to overcome. From the perspective of patients and healthcare providers, maximizing efficacy while concurrently mitigating side effects continues to be the main objective. From the view of the majority of drug development companies, market share, profitability and their fiduciary responsibility to shareholders drive corporate decision-making. In the type of political and economic model that is found in the United States, governmental bodies can only do so much to help bridge the two distinctive goals between the public and drug developers. At some point, we hope that more drug companies, like Grünenthal, will make the difficult but necessary decision to value patient safety and wellbeing of children over corporate profits. Grünenthal has assumed the burden of providing well-designed studies in both the adult and pediatric population to define safe prescription regimens, ideally, before drugs go to market. In the world of pain medicine, this prospective approach will be expected to lead to a reduction of inappropriate prescribing. This will benefit not only the patient but may also reduce the opioid burden that is faced on an international scale.

\section{Disclosure}

Dr. Elliot Krane has many years of experience consulting for governmental agencies as well as major pharmaceutical companies, including Gruenenthal, which is mentioned in this editorial. The authors report no other conflicts of interest in this work.

\section{References}

1. Pharmapproach. List of pharmaceutical companies in United States of America - pharmapproach. Pharmapproach.com; 2020. Available from: www.pharmapproach.com/list-of-pharmaceutical-companies-inunited-states-of-america/14/. Accessed March 15, 2021.

2. Munos B. 2018 new drugs approvals: an all-time record, and a watershed. Forbes, Forbes Magazine; 2019. Available from: www. forbes.com/sites/bernardmunos/2019/01/14/2018-new-drugs-approvals -an-all-time-record-and-a-watershed/. Accessed March 15, 2021.

3. Center for Drug Evaluation and Research. New Drug Therapy Approvals 2019. U.S. Food and Drug Administration, FDA. Available from: www.fda.gov/drugs/new-drugs-fda-cders-newmolecular-entities-and-new-therapeutic-biological-products/new-drugtherapy-approvals-2019. Accessed March 15, 2021.

4. Center for Drug Evaluation and Research. Development of opioids in pediatric patients: conclusions. U.S. Food and Drug Administration, FDA. Available from: www.fda.gov/media/107946/. Accessed March $15,2021$. 
5. Eerdekens M, Beuter C, Lefeber C, van den Anker J. The challenge of developing pain medications for children: therapeutic needs and future perspectives. J Pain Res. 2019;12:1649-1664. doi:10.2147/JPR.S195788

6. Muse D, Tarau E, Lefeber C, et al. Pharmacokinetics, safety, and efficacy of tapentadol oral solution for treating moderate to severe pain in pediatric patients. J Pain Res. 2019;12:1777-1790. doi:10.2147/JPR.S197039

7. Finkel JC, Goldberg J, Rosenburg R, et al. First evaluation of tapentadol oral solution for the treatment of moderate to severe acute pain in children aged 6 to <18. J Pain Res. 2019;12:1925-1936. doi:10.2147/JPR.S197348

8. Watson E, Khandelwal A, Freijer J, van den Anker J, Lefeber C, Eerdekens M. Population pharmacokinetic modeling to facilitate dose selection of tapentadol in the pediatric population. J Pain Res. 2019;12:2835-2850. doi:10.2147/JPR.S208454
9. Beuter C, Volkers G, Radic T, Goldberg J, van den Anker J. Efficacy and safety of multiple doses of tapentadol oral solution in the treatment of moderate to severe acute pain in children aged 2 to $<18$ years - a randomized, double-blind, placebocontrolled trial. J Pain Res. 2019;12:3099-3112. doi:10.2147/ JPR.S207010

10. Slater R, Moultrie F, Bax R, et al. Preterm health: time to bridge the evidence gap. Lancet. 396(10255):872-873. doi:10.1016/S01406736(20)31977-2

\section{Publish your work in this journal}

The Journal of Pain Research is an international, peer reviewed, open access, online journal that welcomes laboratory and clinical findings in the fields of pain research and the prevention and management of pain. Original research, reviews, symposium reports, hypothesis formation and commentaries are all considered for publication. The manuscript management system is completely online and includes a very quick and fair peer-review system, which is all easy to use. Visit http:// www.dovepress.com/testimonials.php to read real quotes from published authors. 